\title{
MUNCHAUSEN SYNDROME BY PROXY - A REAL PEDIATRIC PROBLEM?
}

\author{
Daniela Pacurar, Maria Runcan, Anca Popescu, Gabriela Lesanu, \\ Dumitru Oraseanu \\ Pediatric Clinic, “Grigore Alexandrescu” Emergency Clinical Hospital for Children, \\ Bucharest
}

\begin{abstract}
Munchausen syndrome and Munchausen by proxy syndrome belong belong to a group of disease called "factitious disorder" and are severe mental disorders having the "end" position for a healthy person to become patient, respectevely to "create" a disease to another person, asking or requiring medical intervention for him/her. Munchausen syndrome by proxy is rare, but it is difficult to be recognized and confirmed, is a form of abuse, particularly against children, potentially lethal, often misunderstood. Many methods are used by adults counterfeiters to induce a false child's condition: poisoning, injury, producing bleeding, infection.

Complaints exposed by the mothers as belonging to the child are not for a personal benefit, but are justified by a desire to be a "hero" mothers and to play the role of the people most attached and thoughtful of their child. Diagnosis should include evaluation of the child, parents and family and is based on suggestive elements: child with multiple health problems that do not respond to treatment or recur under proper therapy, laboratory investigations discrepancies, child's signs and symptoms disappear in the absence of the parent.

The false disease of the child, intentionally distorted described by adult, do not realy affect him/her, but the diagnostic process and medical treatment can cause pain and discomfort. Ethical and legal issues associated with MSBP involves healthcare professionals by the medical consequences on the child as a result of false complains described by the parent.

Education of patient, family and medical personnel is a very important step in the recognition, prevention and treatment of MSBP.
\end{abstract}

Keywords: Munchausen by proxy syndrome, child

Richard Asher in 1951 described a bizarre entity characterized by deliberate falsification of the disease's history, in order to take advantage og medical examinations invasive or non-invasive. This condition paid the attention of many doctors and psychologists, initially called "Munchausen syndrome". (1) In 1977 Meadow published two cases, called "Munchausen Syndrome by Proxy" in which the child's symptoms were caused and/or invented by his mother!! Since then, Munchausen syndrome by Proxy was recognized as a form of child abuse. (2)

Munchausen syndrome and Munchausen syndrome by proxy, having the "end" position for a healthy person to become patient, belong to a group of disease called "factitious disorder" ("disorders unnatural, artificial, fake") and represent severe mental disorders classified in Diagnostic and Statistical Manual of Mental Disorders, Fifth Edition (DSM-5). (3-5)

"Factitioius Disorders" are a heterogeneous category of psychological disorders with many medical, ethical or legal issues, comprising at least 3 entities well definited:

- "factitious Disorder Imposed on self Author" or Munchausen syndrome (MS) is a serious mental disorder in which an apparently healthy person try to convince people arround that is sick without a material or financiar benefit. $(3,6)$

- "factitious disorder Imposed on other Author" previously called "Munchausen syndrome by Proxy" (SMBP) is a serious mental 
disorder in which a person "imagine" a disease to another person requesting or requiring medical intervention for this. (5)

- Munchausen by Internet was added as a separate entity since 2000 , the entity still not classified in DSM-5

The severity of these disorders can range from mild (counterfeit or exaggerated symptoms) to severe (self-harm/mutilation). The difficulty of diagnosis and treatment of these disorders "mysterious" causes many medical ethics issues, medical and psychological treatment are important in preventing recurrent and "self-injuries". $(4,6)$

\section{MUNCHAUSEN SYNDROME}

Munchausen syndrome is a mental disorder (most likely belonging to the psychiatric pathology) associated with severe emotional difficulties, expressed by hospital patient dependency with the aim to get attention and assistance of the medical team and to become patient, without any material or financial benefits.

The important element of this desorder consists in repeated or exaggerating symptoms mimicking organic diseases, acute and dramatic, counterfeiting laboratory test, in search of any treatment. The patient simulates conscious and clear the disease as corerct as in "the medical books".

American Psychiatric Association has established criteria for classification of patients with MS according to Diagnostic and Statistical Manual of Mental Disorders, Fifth Edition (DSM-5) $(4,8)$.

- Falsifying physical or physiological signs and symptoms and inducing injury or disease on self (most commonly the presence of at least 2 episodes);

- The individual is presented as others as a sick, injured or suffering person;

- Behavior remains constant and obvious even without rewards;

- Behavior can not be better explained by any other psychiatric or mental condition.

\section{MUNCHAUSEN SYNDROME BY PROXY (MBP)}

"Factitious disorder imposed on another person" (by proxy) has as essential feature the simulation or "production" of another person, healthy, most often a child or a person in care, physical or psychological signs and symptoms without any real evidenece of a mental of physical disease. However this syndrome is rare, but it is difficult to recognize and confirm it. $(8,9)$

American Psychiatric Association, in the American Psychiatric Association's Diagnostic and Statistical Manual of Mental Disorders, Fifth Edition (DSM-5), (3) includes in the category of "factitious Disorders by proxy" Munchausen syndrome by Proxy (MSBP), $(2,5)$ MSBP is a form of abuse, particularly against children, potentially lethal, often misunderstood and unrecognized. In 2002, the term "pediatric condition falsification" (PCF) was introduced by the American Professional Society of the Abuse of Children (APSAC) to describe the condition of child abuse. (5)

Munchausen by proxy is defined as a group of symptoms and signs wherein the condition is simulated or induced to the child by a parent/caregiver (in loco parentis), the child is presented as ill, for investigation and medical treatment frequently being the subject to multiple medical procedures, knowledge about the disease the child are denied by the adult person accompanying the child and the acute symptoms and signs disappear when the child is separated from the accompanying adult.

Munchausen Syndrome by Proxy is a mental disorder to an adult (mostly mothers) who is trying to obtain medical attention using another person: his own child which is used as a surrogate. (9) False affection of the child intentionally false described by an adult do not affect realy the child, but the diagnostic process and the medical treatment can cause pain and discomfort. The adult may induce injuries or cause different types of child illness (intravenous line contamination, poisoning). Most cases of MSBP combines two possible mechanisms. (10)

MSBP is a particular combination of physical, psychological or medical neglect and inadequate treatment, in which the medical team is certain and active involved. (11) It is recognized now as the only lethal form of maltreatment, extremely complex, known today. MBP Syndrome is a public health tragedy, which, paradoxically, was and is largely hidden from the public attention, although there are over 500 professional articles and books about the subject.

Complaints exposed by the mothers as belonging to the child are not for a personal benefit, but are justified by a desire to be a "hero" mothers and to win the role of the people most attached and thoughtful of their child. There have been described cases of victims of MSBP who develop MS or continue to transmit the "pattern" MBP on their children. $(10,11)$ 


\section{EPIDEMIOLOGY}

MBP syndrome incidence and prevalence are not accurately known in US. (12)

Studies realized on a short period show incidence of 2.8-2.9 per 100,000 children under 1 year and 0.5 per 100,000 children aged 1 year to 16 years old, with a mortality between $9 \%$ and $22 \%$ of cases. Studies in Europe show a mortality by syndrome MBP between $6-10 \%$ of cases. (4,13-15) Threequarters of patients are complaining of symptoms related to nervous system. (15)

Every year 1,200 new cases with MSBP are reported in US, but it supposed that this number is exaggerated and, actually, it could be only about 200 cases/year. Over 700 cases have been reported in 52 countries, but these are the most severe cases, leading to the idea of underestimating the phenomenon. The true prevalence is not known. Many cases less severe are not reported, and even remain undetected because of the hidden nature of the abuse. (14)

In a group of patients with asthma, the MSBP phenomenon was reported in $1 \%$ of patients and in another group, with food allergies prevalence was $5 \%$. (16)(17)

The abusive behavior typically begins early in life of MSBP victim, infants and toddlers are often exposed. According to studies the average age of diagnosis of children exposed is between 20 to 39.8 months, and also the older children, even teenagers, may be affected by the behavior of adults whith take care of them or may be involved in counterfeiting symptoms. (14, 18-19)

Age of diagnosis varies with the type of symptom accused: apnea and the seizures are most common in the age of 1-3 months last to the age of 6-12 months or until the patient died. $(10,20,21)$

A recent study indicates that by the time the one case of a child exposed to a MSBP is finally recognized as such disorder, $25 \%$ of sick child or siblings have already died, the most likely being previous victims of the same sick "parent". Many studies show that between $8.5 \%$ and $25.8 \%$ of siblings were abused in the same way. (18-20)

To hide this behavior, the family often change residence, the doctor or the hospital to which it is addressed with the child. Only when the same pattern of symptoms was found in the family's second child (or third or fourth), medical and legal authorities had to realize that motherhood can be transformed into an unusual type of maltreatment, related diseases that, unlike physical molestation, defies categorization.
Boys and girls are in a equal proportion exposed to MSBP. No different racial predisposition of the victims are noticed, but abusing mothers are predominantly white race. A meta-analysis of the literature regarding the reporting of MSBP cases shows that this is not a phenomenon present only in industrialized and rich countries with a high-performance medical system. (20)

Although in practice in over $95 \%$ of cases the mother is the person who is abusing, in a study published in 2003, documented on 451 cases of MSBP, was observed that only $76 \%$ persons who asked repeated for the children unnecessary medical assistance were patients mothers, fathers in $6.7 \%$ of cases and in $17 \%$ of cases others persons taking care of the child. (10)(21)

In the few studies that identified the father as a person who abuses, that father has not the parentdedicated profile but disturbed and unstable emotional person. (10)

\section{DIAGNOSIS}

The most important thing is that diagnosis should include evaluation of the child, parents and family (dynamic evaluation)! considering the following points $(22,23)$.

- Children who have one or more health problems that do not respond to treatment or recur often under proper therapy, requiring hospitalizations, consultations, investigations or repeated treatments.

- Children whose laboratory investigations are in real discrepance with the history of the disease and complains. (24)

- Signs and symptoms of the disease disappear in the absence of the parents.

- The parent has many and rich medical knowledge, is interested in the details about his own child, but also about other patients diseases (can work in the medical field, or consult the speciality medical textbooks or inform for medical information by internet searching). He doesn't need a high education, he should only be convincing.

- The parent may have symptoms similar to the child, or a history of similar disease.

- There could be noticed a tensiond or cold relationship between the two parents, family conflict or separated families.

- Family history of illnesses or deaths hard to explain, or even inexplicable.

- The parent is inexplicable calm vis-à-vis the serious medical condition of the child or, 
conversely, is dissatisfied with diagnostic and calls other procedures for investigation, surgery, second opinion of other specialists, or even transfer the child in units with greater opportunities. (23)

- Parent which describes dramatic events (fires, car accidents, etc.) that impact on child and family health. (5)

MSBP is a condition whose diagnosis is difficult, in most cases, after medical and psychiatric evaluation. The average time between of the "onset of symptoms" to the diagnosis established is evaluated in a study made by Feldman to be 4.5 years, in another study by Rosenberg at 14.9 months and in a stugy of Sheridan at 21.8 months, that means a very long period in a life of an infant. $(21,18)$

Tragically, the child victims learn quickly that they will attract attention and affection of the mother if plays the role of sick person in faco of doctors and medical team. They will accept this spirit and they will grow and develop Munchausen syndrome or will continue the parental model making the same think with their children at their turn. $(25,26)$ Apparently getting personal satisfaction and gratitude of the family by falsifying the disease, makes this condition to develop for several generations. (18)

A lot of methods are used by adults counterfeiters to induce a false affection in their child, but most can be summarized in four categories. $(11,27)$

- Poisoning: administration of ipeca salts, insulin, laxatives, lorazepam, caustics, amitriptyline, clonidine, diphenhydramine;

- Injury: choking, ingestion of foreign bodies, recurrent conjunctivitis, a fracture that heals;

- Production of bleeding: hematuria, gastrointestinal bleeding, hematoma;

- Infection: application of urine or feces, dirt or coffee grounds wounds, injecting urine in the catheters or orthopedic devices, contamination with saliva.

Considering these main ways of aggression, Rosenberg by analyzing the patient's presenting symptoms, observed that $44 \%$ of patients had bleeding, $42 \%$ acute convulsions, $19 \%$ have central nervous system depression, $15 \%$ apnea, $11 \%$ diarrhea, vomiting $10 \%, 10 \%$ fever and $9 \%$ rashes. Other complains present in the MSBP are: allergies, behavioral disorders, asthma attacks, cyanosis, decreased appetite, urination related problems, sexual abuse, dermatological problems. (18) In a study made by Sheridan on 451 cases of MSBP presented in 154 medical articles is noticed that the average number of complaints/patient is three. (21)
Some warning signs which can suggest MSBP diagnosis would currently be identified, related to the child or related to the persons who take care of him/her. (11)

Signs related to the child: $(11,27,28)$

- Age under 5 years old at the time of onset of symptoms;

- History of repeated contact with medical staff;

- The child sescribes some symptoms present only in the presence of the mother or the caregiver;

- Charging of multiple symptoms, but vague and confusing;

- Standard treatments are not effective in the resolutions of the child's complaints;

- In the medical familial history could noticed dead brothers in unclear, complicated circumstances;

- The patient's father is emotionally distant or absent in the child's life;

- Worsening symptoms when approaching the time of discharge.

The characteristics of the mother or caregiver are:

- The mother lets the impression that is very careful and dedicated, but constantly asks for further testing, surgical procedures, specialist appointments and repeated hospitalizations.

- She feels comfortable surrounded by medical team, makes friends among them or other patient's family members.

- She presents many medical knowledge, more than the general population.

- She has personal opinions regarding the child's disease and describes the symptoms as corerct as "in the medical textbooks".

- She has a unique ability in denying the opinions of medical staff.

- She becomes aggressive and hostile when her thoughts are exposed and revealed.

In MSBP syndrome, physicians and healthcare professionals become unwittingly parteners in producing of the child's suffering, being conditioned to listen what the relatives of the child presented to them.

Often parents of children with MSBP appear as a nice people, polite, attentive, well accomodated at the hospital, very frindly with the staff or with other patients relatives. As parents, they seemed to be loyal, careful, admirable parents. (29) Most mothers of victims of MSBP are respectful and flattering, but can become aggressive when they fear to lose the attention, are exposed and unmasked or are in contradiction whit their medical staff. $(30,31)$ 
When medical team realized the deception, they are angry and frustrated defending a new parentphysician conflict. (32) It is correct that the parents affirmations are the best guide to discover what is wrong with the child. A doctor must fundamentally change their attitude to accept that something in false in the parents stories because the test results are normal, no treatment ever works, that any analysis would never be enough for diagnosis, and the child parent could be described as being guilty of abuse.

Medeea syndrome is a variant syndrome of MSBP. Medea syndrome is a psychotic state requiring murder or attempted of murder of their children, as a form of punishment of the husband/wife, considered guilty for real or imaginary reasons. It is relatively common situation and is included in the cathegory, crimes of passion, by the Courts and Media.

MSBP disorder must be distinguished by a number of conditions less aggressive and less forensic or psychological implications as: (10)

- Vulnerable child syndrome: some parents are extremely anxious regarding their child especially when he gets sick frequently or is diagnosed with a serious illness. Some parents are stressed and projects their stress on their children. These parents pay exaggerated the attention of medical staff, but this fear can be identified and treated. Often the mother described herself as being "neurotic" or emotionally unstable and main fear was for the diagnosis of cancer or leukemia. This condition is called hypochondria by proxy.

- Persons who request protection (social), mothers bring their children into hospital in order to solve their own problem related to anxiety or depression. These mothers gladly accepts interventions "on" them, by contrast with MSBP mothers who refuse these interventions. Often these mothers have a history of family violence, unwanted pregnancies or single-parent family.

- Mothers addicted on doctor: This is a type of MSBP occurring in older children whose mothers are convinced that their children are sick and, using a single sign or symptom, try to convince the doctors of the child's illness. The symptom often used in this type of condition is an allergy, mothers become obsessed with this disease and creates bizarre diets. These mothers are more hostile, resistant and distrustful, demanding and dissatisfied at doctors activity.
- Patients noncompliant are patients who are actively or passively fail to manage a child's treatment for a diagnosis, sometimes with an severe outcome. These parents either deny the reality, or not understand the situation, or are deprived of responsibility and let children to develop the worsening disease despite efforts by medical personnel. This attitude can be classified as neglect or ignorance, but it is certainly different from MSBP.

Regarding the prognosis of MSBP it could be observed that it produces physical and mental suffering for the child. In addition, the developmental delay physical and mental is proportional to the period of evolution of the syndrome. (33)

\section{LEGAL AND ETHICAL ISSUES OF MUNCHAUSEN SYNDROME BY PROXY (MSBP)}

In many countries legislation is ambiguous about this syndrome and the guilty of the affected abuser. In Romania this syndrome is recognized as a form of child abuse by Decision no. 49 of 19 January 2011, published in MO, updating Law no. $217 / 2003$ on domestic violence, that states that "Munchausen Syndrome by transfer (MBP) is the artificial creation of a child fake diseases by the parent; disease is induced by administration of drugs for poisoning, or by supporting the existence of symptoms in children who have never been confirmed by the specialists. In both cases, many parents require medical or surgical investigation, abusing the child repeatedly. Any functional sign can be invoked by parents to get painful and intrusive investigations and proceedings for the child. (34)

The reasons justifying the behavior of the abuser parent with MSBP may be: $(11,21,35,(36)$

- Gaining sympathy, attention, respect and public recognition by playing the role of a devoted mother, only one able to love and to save the child and, in the same time, of a neglected wife in the reason to have help and support from the family, to escape of everyday life responsibilities. Maintaining permanent lie requires others' attention and the child suffering.

- Demonstrating to others a high level of medical knowledge and absolute control over the child's health.

- Interest to participate in the social life of the hospital, the charitable activities.

Mothers of MSBP victims can be so compelling that, friends, family members and even medical 
team defends them and believe they are wrongly accused when unmasking.

\section{MS OR MSBP IMPACT ON THE MEDICAL STAFF}

In this condition a special "triangle" motherchild- doctor is present. The problem is if the guilty parent and medical staff are partners in child suffering challenge. Parents show a continuing need of medical attention for their child fabricating diseases. The medical staff is, professional and intellectual incited by the unsolved cases after multiple investigations and evaluations and are very interested in these patients. $(30,36)$

Ethical and legal issues associated with MSBP involve the medical team by point of view of the medical consequences on the child, as a result of counterfeiting reality by parents. MSBP is completely different from other forms of maltreatment or child abuse through the active involvement of medical personnel in producing morbidities of the child. $(30,32)$

\section{MSBP ATYPICAL FORM OF CHILD ABUSE}

MSBP faced to other forms of physical child abuse, has the particularity of the degree of premeditation: in many forms of child abuse the child is punished for various actions, but in MSBP, aggression seems not to be provoked. $(11,32,36)$ MSBP could be seen as a life-threatening condition for possible iatrogenic complications (11).

\section{Therapy and Patient Education}

Education of patient, family and medical personnel is a very important step in the recognition, prevention and treatment of MSBP. Patient education should include the acquisition of techniques for adaptation and stress management. Family education includes a presentation of models with this condition, found in the same family in order to recognize the first signs, for the application of appropriate therapy.

Assessment should not be limited to the child involved but should also include brothers and other family members. Psychotherapy should be a therapeutic method in benefit of the mother, affected children and other family members. Pharmacological drug therapy may be necessary if the mother presents psychiatric disorders and she may be a subject to a treatment. The family requires careful long-term monitoring because of the danger of repeating the same behavior in a new location. In severe cases, treatment and cure of MSBP is achieved only by separating the child from the abuser parent ("total parentectomy"). This ensures child safety, and reversibility immediately of all complaints. $(5,30)$

\section{MUNCHAUSEN BY INTERNET}

Munchausen by Internet is a type of "factitious disorder" which refers to people using Internet, who access medical sites or online support groups in order to be classified as "sick". (4) Several behavioral patterns of persons who had Munchausen by Internet were described: (37)

- The severity of the condition and period of the evolution of the disease is in contrast with the behavior of the person who posts (people in septic shock posts daily). Serious and critical situations are followed up by spectacular recoveries or miraculous cures. The emergency situations from the mediacl history or worsening of the disease are described with an unjustified joy in the reason to create an immediate reaction.

- Symptoms and complaints are exaggerated, showing a lack of understanding of the pathophysiological process of the disease.

- When the group's attention is lost or is going to another subject, "patient" returns with extraordinary information: aggravation of the illness or death of a family member.

- The user denied all the contacts except the Internet access, refuse visits to the doctors or telephone contact.

\section{CONCLUSIONS}

Munchausen Syndrome by Proxy and MS represent and inexhaustible topic, particularly interesting, and many doctors should have knowledge about both, even from the period of residency or the first year of study. It is important to recognize it and properly diagnose patients, which would lead to a correct therapeutic plan in the shortest time. Another reason for understanding these types of disorders is to protect us from accusations of malpractice, because these individuals, unsatisfied in their needs and desires might make legal complaints. 


\section{REFERENCES}

1. Asher R. Munchausen's Syndrome. Lancet. 1951; 1:339-41.

2. Meadow R. Munchausen syndrome by proxy. The hinterland of child abuse. Lancet. Aug 13 1977; 2(8033):343-5.

3. American Psychiatric Association. Diagnostic and Statistical Manual of Mental Disorders. Fifth Edition. Arlington, VA: American Psychiatric Association; 2013: 324-6.

4. Factitious Disorder Imposed on Self Author: Todd S Elwyn, MD; Chief Editor: Eduardo Dunayevich, MD http://emedicine.medscape.com/ article/291304-overview

5. Factitious Disorder Imposed on Another Author: Guy E Brannon, MD; Chief Editor: Eduardo Dunayevich, MD http://emedicine.medscape. com/article/295258-overview \#aw2aab6b2b8

6. http://www.mayoclinic.org/diseases-conditions/factitious-disorder/ basics/risk-factors/con-20031319

7. Munchausen by Internet http://en.wikipedia.org/ wiki/M\%C3\%BCnchausen_by_Internet

8. Diagnostic and Statistical Manual of Mental Disorders, Fifth Edition Edited by American Psychiatric Association oct 2014, http://dx.doi. org/10.1176/appi.books.9780890425596

9. Galvin H.K., Newton A.W., Vandeven A.M. Update on Munchausen syndrome by proxy. Curr Opin Pediatr. Apr 2005; 17(2):252-7.

10. Munchausen by Proxy visual diagnosis of child abuse on cd-rom lecture series

11. Monsters in the Closet: Munchausen Syndrome by Proxy Laura Criddle, RN, PhD, ACNS-BC, CCRN, CCNS CriticalCareNurse Vol 30, No. 6, DECEMBER 2010

12. Forsyth B. 102. In: Lewis M, ed. Child and Adolescent Psychiatry. $3^{\text {rd }}$ ed. Philadelphia, Pa: Lippincott Williams and Wilkins; 2002:1223-1230.

13. Schreier H.A., Libow J.A., eds. Hurting for Love: Munchausen by Proxy Syndrome. New York, NY: Guilford; 1993.

14. McClure R.J., Davis P.M., Meadow S.R., Sibert J.R. Epidemiology of Munchausen syndrome by proxy, non-accidental poisoning, and non-accidental suffocation. Arch Dis Child. Jul 1996; 75(1):57-61.

15. Marcus A., Ammermann C., Klein M., Schmidt M.H. Munchausen syndrome by proxy and factitious illness: symptomatology, parentchild interaction, and psychopathology of the parents.

16. Godding V., Kruth M. Compliance with treatment in asthma and Munchausen syndrome by proxy. Arch Dis Child. Aug 1991; 66(8):956-60.

17. Warner J.O., Hathaway M.J. Allergic form of Meadow's syndrome (Munchausen by proxy). Arch Dis Child. Feb 1984; 59(2):151-6.

18. Rosenberg D.A. Web of deceit: a literature review of Munchausen syndrome by proxy. Child Abuse Negl. 1987; 11(4):547-63.

19. Feldman M.D., Brown R.M.A. Munchausen by Proxy in an international context. Child Abuse Negl. 2002; 26(5):509-524.

20. Meadow R. Suffocation, recurrent apnea, and sudden infant death. J Pediatr. Sep 1990; 117(3):351-7.
21. Sheridan M.S. The deceit continues: an updated literature review of Munchausen Syndrome by Proxy. Child Abuse Negl. Apr 2003; 27(4):431-51.

22. Squires J.E., Squires R.H. Jr. Munchausen syndrome by proxy: ongoing clinical challenges. J Pediatr Gastroenterol Nutr. Sep 2010; 51(3):248-53.

23. Kucuker H., Demir T., Oral R. Pediatric condition falsification (Munchausen syndrome by Proxy) as a continuum of maternal factitious disorder (Munchausen syndrome). Pediatr Diabetes. Dec 2010; 11(8):572-8.

24. Kenedi C.A., Shirey K.G., Hoffa M., Zanga J., Lee J.C., Harrison J.D., et al. Laboratory diagnosis of factitious disorder: a systematic review of tools useful in the diagnosis of Munchausen's syndrome. N Z Med J. Sep 9 2011; 124(1342):66-81.

25. Saad G. Munchausen by proxy: the dark side of parental investment theory? Med Hypotheses. Dec 2010; 75(6):479-81.

26. Libow J.A. Beyond collusion: active illness falsification. Child Abuse Negl. 2002; 26(5): 525-536.

27. The Nemours Foundation. Munchausen by proxy syndrome. November 5, 2007. Available at http://www.kidshealth.org/parent/ general/sick/munchausen.html. Accessed January 4, 2008' December 12, 2013.

28. Morrell B., Tilley D.S. The role of nonperpetrating fathers in Munchausen syndrome by proxy: a review of the literature. $J$ Pediatr Nurs. Aug 2012; 27(4):328-35.

29. Pasqualone G.A., Fitzgerald S.M. Munchausen by proxy syndrome: the forensic challenge of recognition, diagnosis, and reporting. Crit Care Nurs Q. 1999; 2(1):52-64; quiz 90-91.

30. Stirling J. Jr, American Academy of Pediatrics Committee on Child Abuse and Neglect. Beyond Munchausen syndrome by proxy: identification and treatment of child abuse in a medical setting. Pediatrics. 2007; 119(5): 1026-1030.

31. Libow J.A. Munchausen by proxy victims in adulthood: a first look. Child Abuse Negl. 1995; 19(9):1131-1142.

32. Donald T., Jureidini J. Munchausen syndrome by proxy: child abuse in the medical system. Arch Pediatr Adolesc Med. 1996; 150(7):753-758.

33. Chafetz M., Dufrene M. Malingering-by-proxy: Need for child protection and guidance for reporting. Child Abuse Negl. 2014 Nov; 38(11):1755-1765.

34. M.O. Hotărârea nr. 49 din 19 ianuarie 2011, publicată în M.O.

35. Fulton D.R. Early recognition of Munchausen syndrome by proxy. Crit Care Nurs Q. 2000; 23(2):35-42.

36. Schreier H.A. Munchausen by proxy. Curr Probl Pediatr Adolesc Health Care. 2004; 34(3): 126-143.

37. Feldman M.D. South Med J. 2000 Jul; 93(7):669-72. Munchausen by Internet: detecting factitious illness and crisis on the Internet. 